Article

\title{
Shear Properties of Asphalt Mixtures under Triaxial Compression
}

\author{
Tuo Huang, Shuai Qi, Hongfu Liu, Huanan Yu® and Sheng Li *
}

Key Laboratory of Highway Engineering of Ministry of Education, School of Traffic and Transportation Engineering, Changsha University of Science \& Technology, Changsha 410114, China; ht@csust.edu.cn (T.H.); 17101030071@stu.csust.edu.cn (S.Q.); 1hf0625@csust.edu.cn (H.L.); huanan.yu@csust.edu.cn (H.Y.)

* Correspondence: lishengttt@csust.edu.cn; Tel.: +86-138-7499-7351

Received: 27 March 2019; Accepted: 2 April 2019; Published: 10 April 2019

\begin{abstract}
In order to study the influences of confining pressure and temperature on the shear properties of asphalt mixtures, triaxial tests were conducted at $40{ }^{\circ} \mathrm{C}, 50{ }^{\circ} \mathrm{C}$, and $60^{\circ} \mathrm{C}$, with the confining pressure ranges from 0 to $1 \mathrm{MPa}$ for the widely used continuous-graded $\mathrm{AC}$ (Asphalt Concrete)-13, open-graded OGFC (Open-Graded Friction Course)-13, and gap-graded SMA (Stone Mastic Asphalt)-13 asphalt mixtures in China. A nonlinear regression/prediction model of triaxial strength for asphalt mixtures was proposed. The results show that confining pressure and temperature had a significant effect on the shear resistance of asphalt mixtures. With increasing temperature, the shear strength of the asphalt mixture gradually decreased due to the decreasing of cohesion strength; the shear strength of the asphalt mixture increased with the increase of confining pressure. Meanwhile, the cohesion strength increased and the friction angle decreased gradually with the increase of confining pressure. When the confining pressure was close to $0.6 \mathrm{MPa}$, the Mohr-Coulomb failure envelope bended down, so the linear Mohr-Coulomb criterion is not suitable to describe the failure behavior of asphalt mixtures. Therefore, a power function failure envelope was put forward to characterize the nonlinear shear properties of asphalt mixtures. The nonlinear evolutional laws of shear parameters, which includes cohesion strength and friction angle, were also proposed for asphalt pavement material and structure design. Among these asphalt mixtures, the gap-graded SMA-13 asphalt mixture exhibited better performance on the resistance to shear failure, and it was recommended as the upper layer material to improve the shear performance of asphalt pavement.
\end{abstract}

Keywords: asphalt mixtures; triaxial test; shear properties; nonlinear Mohr-Coulomb failure envelope

\section{Introduction}

By the end of 2018, 142,500 km of expressway had been built in China, most of which are composed of the semi-rigid base asphalt pavement structure. The use of semi-rigid base reduces the deflection of the pavement, as well as the bending stress at the bottom of the asphalt layer [1]. Hence, the overall deformation resistance of the pavement structure is greatly enhanced. However, the shear stress in the surface layer is increased inadvertently [2]. Besides this, the overloading phenomenon is widespread in China. Therefore, it is of great importance to enhance the strength, especially the shear strength of asphalt mixtures in the hot areas in China [3]. Otherwise, the rutting damage will appear in the asphalt pavement due to insufficient capacity of shear resistance [4-6]. Thus, the performance of asphalt pavement will be greatly reduced, and the service life and service level of pavement will be seriously affected. 
In previous studies, the triaxial test and shear formula have been used for the analysis of shear resistance for asphalt mixtures [7-9]. In recent years, the Strategic Highway Research Program (SHRP) has proposed three types of tests to evaluate the shear deformation of materials, including triaxial creep and repeated loading tests, simple shear creep and repeated loading tests, and uniaxial creep and repeated loading tests $[10,11]$. However, these tests have not been widely used in practice in China because of their time consumption. In addition, Ji et al. developed a method for determining the criterion of shear strength based on the large accelerated loading test [12]. Nevertheless, the large accelerated loading test is expensive and complicated to operate. Only a few agencies in China have this equipment, which makes it difficult to be widely used [12]. In order to simplify the test method, Zhang et al. proposed the partial triaxial compression test to evaluate the shear resistance of asphalt mixtures [13]. Although this test method inherits many advantages of triaxial test, its applicability needs further verification because it is a new test method. In order to ensure the asphalt surfaces have adequate shear strength, the Specifications for Design of Highway Asphalt Pavement (JTG D50-2017) in China inspects the integrated penetration strength of the whole asphalt concrete surface layers; the essence is to control the shear strength from the view of asphalt mixtures. Although the uniaxial penetration test was proposed in the specification to simulate the complex stress states of asphalt materials in the pavement structure [14-16], it is unreasonable to solve the friction angle and cohesion strength by linear Mohr-Coulomb theory according to the combined tests of uniaxial penetration and unconfined compression, the reason being that the nonlinear shear properties of asphalt mixture were not taken into account [17-19].

As mentioned above, on one hand, the shear failure of asphalt pavement materials usually occurs under the effect of overload and heavy load during the hot summer season [20]. On the other hand, the triaxial test has many advantages such as to simulate the complex stress state of the pavement structure, and to solve the friction angle and cohesion strength for asphalt pavement materials and structure design [21-23]. However, the use of the linear Mohr-Coulomb theory affects the accuracy of materials and structure design for asphalt pavement. Therefore, the triaxial tests were carried out at various temperatures and confining pressure levels for the widely used continuous-graded AC (Asphalt Concrete)-13, open-graded OGFC (Open Graded Friction Course)-13, and gap-graded SMA (Stone Mastic Asphalt)-13 asphalt mixtures in China [24]. Based on the results, a nonlinear Mohr-Coulomb failure envelope was established, and the nonlinear evolutional laws of cohesion strength and friction angle were also proposed. All of these are important for the design of asphalt pavement materials and structures.

\section{Materials and Test}

\subsection{Materials}

The mechanical responses of typical pavement structures under heavy tires were analyzed in Reference [2], and the results indicated that the maximum shear stress was generally located at the bottom of upper layer of asphalt pavement. Hence, the triaxial tests were conducted for the widely used upper surface layer materials of asphalt pavement in China, including the continuous-graded AC (Asphalt Concrete)-13, open-graded OGFC (Open Graded Friction Course)-13, and gap-graded SMA (Stone Mastic Asphalt)-13 asphalt mixtures. The gradations were plotted in Figure 1 and the mixture designs are listed in Table 1; the basalt was used as aggregate, the SBS (Styrene Butadiene Styrene) modified bitumen, which is one of the most commonly used modified bitumen in pavement industry, was used as the binder $[25,26]$. The lignin fiber was used as a component of SMA-13 asphalt mixture. The basic properties of SBS modified bitumen were provided in Table 2 [27]. 


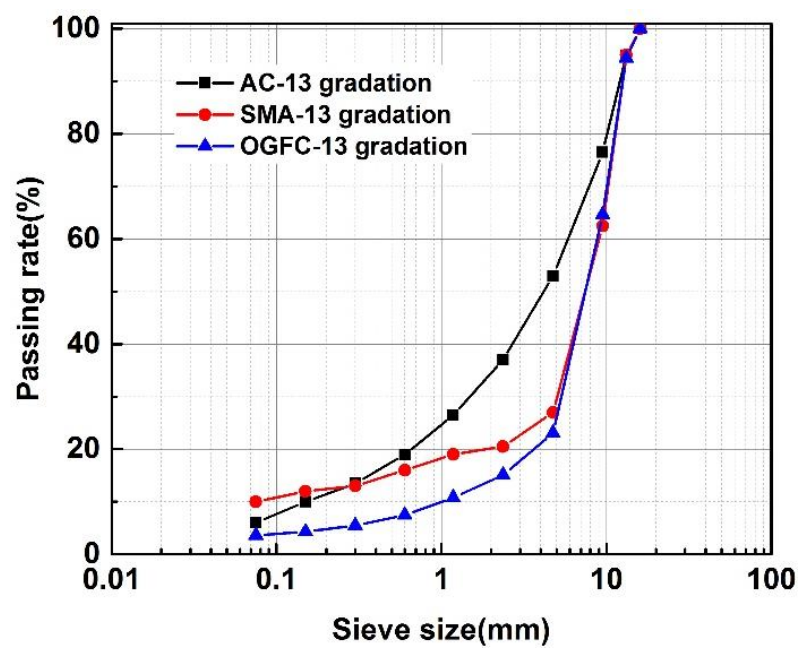

Figure 1. Chart of AC (Asphalt Concrete)-13, SMA (Stone Mastic Asphalt)-13, and OGFC (Open Graded Friction Course)-13 gradations.

Table 1. Gradation and mix composition of asphalt mixtures.

\begin{tabular}{cccc}
\hline Mixture Type & AC-13 & SMA-13 & OGFC-13 \\
\cline { 2 - 4 } Sieve Size (mm) & \multicolumn{3}{c}{ Passing Rate (\%) } \\
\hline 16 & 100 & 100 & 100 \\
13.2 & 95 & 95 & 94.4 \\
9.5 & 76.5 & 62.5 & 64.7 \\
4.75 & 53 & 27 & 23.1 \\
2.36 & 37 & 20.5 & 15.1 \\
1.18 & 26.5 & 19 & 10.8 \\
0.6 & 19 & 16 & 7.5 \\
0.3 & 13.5 & 13 & 5.5 \\
0.15 & 10 & 12 & 4.3 \\
0.075 & 6 & 10 & 3.6 \\
Air void & $5.7 \%$ & $6.2 \%$ & $5.4 \%$ \\
Optimum asphalt-aggregates weight ratio & $4.5 \%$ & $4.3 \%$ & $19.5 \%$ \\
\hline
\end{tabular}

Table 2. Basic properties of the asphalt binder.

\begin{tabular}{ccc}
\hline Test & SBS Modified Bitumen & Technical Requirements \\
\hline Penetration $\left(25^{\circ} \mathrm{C}\right)(0.1 \mathrm{~mm})$ & 55.9 & $30 \sim 60$ \\
Penetration index & 0.53 & $\geq 0$ \\
Ductility $\left(5^{\circ} \mathrm{C} / \mathrm{cm}, 5 \mathrm{~cm} / \mathrm{min}\right)$ & 34.2 & $\geq 20$ \\
Softening point $\left({ }^{\circ} \mathrm{C}\right)$ & 79.4 & $\geq 60$ \\
Viscosity $\left(135^{\circ} \mathrm{C}, \mathrm{Pa} \cdot \mathrm{s}\right)$ & 2.30 & $\leq 3$ \\
\hline
\end{tabular}

\subsection{Specimen Preparation}

Current specification of Standard Test Methods of Bitumen and Bituminous Mixtures for Highway Engineering (JTG E20-2011) in China states that the cylindrical specimen with a diameter of $100 \mathrm{~mm}$ and a height of $150 \mathrm{~mm}$ can be used for triaxial test, the cylindrical specimen can also be tested with other sizes if needed. Meanwhile, the specimen for uniaxial compression test (that is the stress state with confining pressure of 0 ) of asphalt mixture in the specification is $100 \mathrm{~mm}$ in diameter and $100 \mathrm{~mm}$ in height. In order to be consistent with the specimen size of the uniaxial compression test, the cylindrical specimen with the diameter of $100 \mathrm{~mm}$ and the height of $102 \mathrm{~mm}$ was obtained by the gyratory compactor. Then, the upper and lower surfaces of the specimen were polished with a double-sided saw to obtain the specimen with a height of $100 \mathrm{~mm}$. 


\subsection{Triaxial Conditions and Setups}

The triaxial test method developed by Zheng and Huang was adopted to conduct the tests. As shown in Figure 2, in this test, the stable confining pressure was applied on the outer cylindrical surface of specimen through the flexible airbag, the axial stress was loaded by a material testing system MTS (Material Testing System) [27,28]. Therefore, the specimen fails at the complex stress state of triaxial compression.

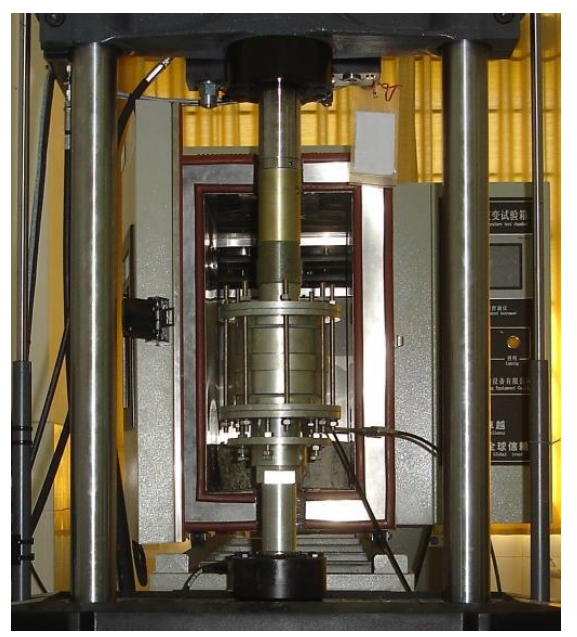

Figure 2. Schematic of triaxial test equipment.

As shown in Figure 3, the highest average temperature of China in July was $32.7^{\circ} \mathrm{C}$. Hence, the daily maximum temperature can reach $40{ }^{\circ} \mathrm{C}$ or more. According to previous studies $[29,30]$, the temperature of the road surface can be $20^{\circ} \mathrm{C}$ higher than the atmospheric temperature in summer. Therefore, three temperatures of $40{ }^{\circ} \mathrm{C}\left(104{ }^{\circ} \mathrm{F}\right), 50{ }^{\circ} \mathrm{C}\left(122^{\circ} \mathrm{F}\right)$, and $60{ }^{\circ} \mathrm{C}\left(140{ }^{\circ} \mathrm{F}\right)$ were chosen as testing temperatures [31]. The axial loading rate was $1 \mathrm{~mm} / \mathrm{min}$ to simulate the effect of static load. In this condition, the asphalt mixture is prone to shear failure. Considering that confining pressure significantly affects the triaxial strength properties of the asphalt mixture [32,33], the confining pressure was set to $0,0.2,0.4,0.6,0.8$, and $1.0 \mathrm{MPa}$, respectively, to analyze the influence of confining pressure. Before the test, the specimen was placed into the temperature control chamber for more than $6 \mathrm{~h}$ to ensure that the temperature of the specimen is consistent with the testing temperature. In addition, the lubricant was smeared on the upper and lower surfaces of the specimen to reduce the friction. During the process of conducting the triaxial test, the confining pressure was firstly applied through the airbag and then the axial load was applied by the MTS until the specimen fails.



Figure 3. Average temperature map of China in July 2017. 


\section{Results and Discussion}

\subsection{Triaxial Strength at $40^{\circ} \mathrm{C}, 50^{\circ} \mathrm{C}$, and $60^{\circ} \mathrm{C}$}

The average values of three effective test results of triaxial strength are presented in Table 3. In the triaxial test, the specimens were mainly represented as shear failure, and some diagonal cracks appeared on the surface of the specimen as shown in Figure 4.

Table 3. Triaxial results of asphalt mixtures.

\begin{tabular}{ccccc}
\hline \multirow{2}{*}{ Mixture Type } & Confining Pressure $\boldsymbol{\sigma}_{1} \mathbf{( M P a )}$ & \multicolumn{3}{c}{ Triaxial Strength $\boldsymbol{\sigma}_{3} \mathbf{( \mathbf { M P a } )}$} \\
\cline { 3 - 5 } & & $\mathbf{4 0}{ }^{\circ} \mathbf{C}$ & $\mathbf{5 0}{ }^{\circ} \mathbf{C}$ & $\mathbf{6 0}^{\circ} \mathbf{C}$ \\
\hline \multirow{3}{*}{ SMA-13 } & 0 & 1.968 & 1.342 & 0.837 \\
& 0.2 & 2.822 & 2.079 & 1.456 \\
& 0.4 & 3.364 & 2.688 & 2.018 \\
& 0.6 & 4.139 & 3.248 & 2.509 \\
& 0.8 & 4.690 & 3.844 & 3.047 \\
AC-13 & 1.0 & 5.284 & 4.350 & 3.506 \\
& 0 & 1.613 & 1.142 & 0.750 \\
& 0.2 & 2.339 & 1.651 & 1.269 \\
& 0.4 & 2.856 & 2.252 & 1.783 \\
& 0.6 & 3.398 & 2.686 & 2.238 \\
OGFC-13 & 0.8 & 4.024 & 3.229 & 2.737 \\
& 1.0 & 4.567 & 3.743 & 3.105 \\
\hline & 0 & 1.183 & 0.842 & 0.657 \\
& 0.2 & 1.835 & 1.465 & 1.153 \\
& 0.4 & 2.397 & 1.941 & 1.605 \\
& 0.6 & 2.796 & 2.388 & 2.059 \\
& 0.8 & 3.207 & 2.801 & 2.407 \\
& 1.0 & 3.599 & 3.243 & 2.766 \\
\hline
\end{tabular}

Note: $\sigma_{3}$ and $\sigma_{1}$ are sorted by absolute values of compressive stresses.

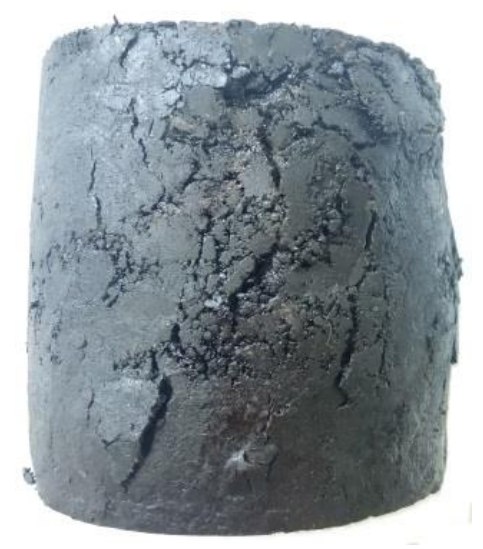

Figure 4. Shear failure of specimen.

Figures 5-7 show the triaxial compressive strength $\sigma_{3}$ of asphalt mixtures under various confining pressure at $40{ }^{\circ} \mathrm{C}, 50^{\circ} \mathrm{C}$, and $60^{\circ} \mathrm{C}$; the sequence of triaxial strength of asphalt mixtures is SMA-13 > AC-13 > OGFC-13. It can be seen from those test results that the triaxial strength is highly influenced by confining pressure and temperature. The triaxial strength increases with the increase of confining pressure, and it increases with the decrease of temperature. All the test results were fitted well with a power function as following:

$$
\sigma_{3}=A \sigma_{1}^{n}+f_{c}
$$


where $\sigma_{3}$ denotes the triaxial compressive strength, $\mathrm{MPa}, \sigma_{1}$ is the confining pressure, $\mathrm{MPa}, f_{c}$ is the uniaxial compressive strength, MPa. $A$ and $n$ are parameters to be determined by least square method. The parameters of this model are listed in Table 4.

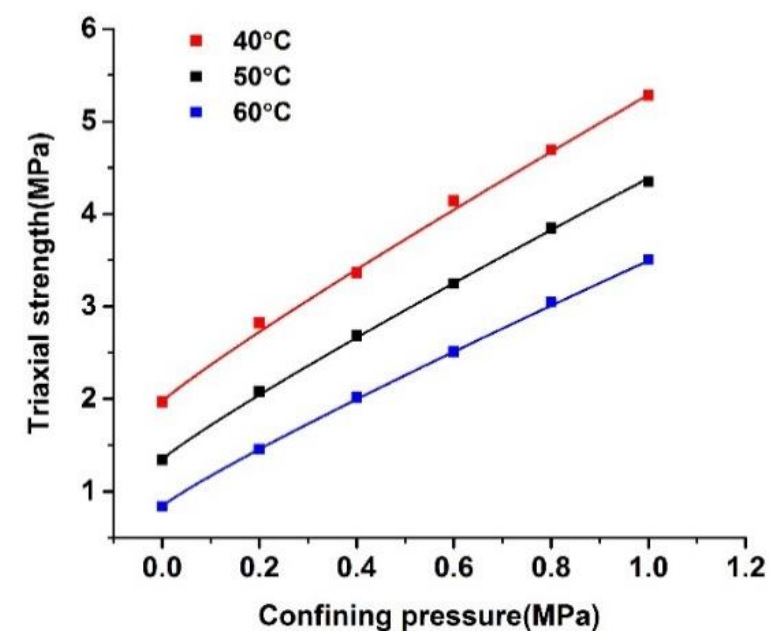

Figure 5. Triaxial results of SMA-13 asphalt mixture.

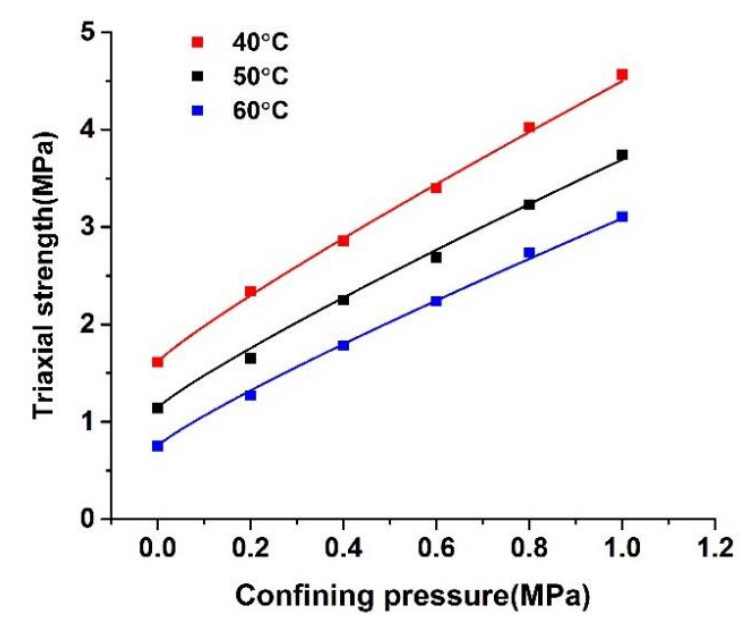

Figure 6. Triaxial results of AC-13 asphalt mixture.

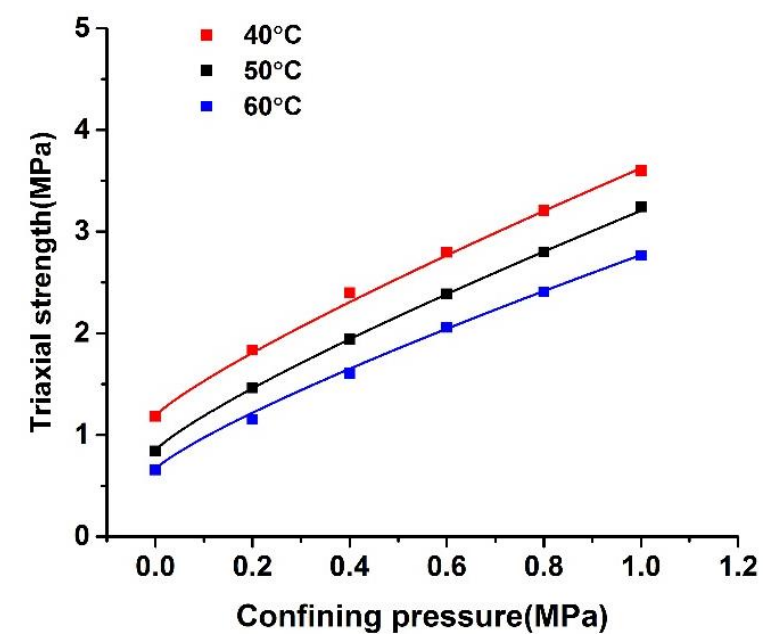

Figure 7. Triaxial results of OGFC-13 asphalt mixture. 
Table 4. Parameters of the triaxial strength model of asphalt mixtures.

\begin{tabular}{ccccccccccc}
\hline \multirow{2}{*}{ Mixture Type } & \multicolumn{3}{c}{$\mathbf{4 0}{ }^{\circ} \mathbf{C}$} & \multicolumn{3}{c}{$\mathbf{5 0}{ }^{\circ} \mathbf{C}$} & \multicolumn{3}{c}{$\mathbf{6 0}{ }^{\circ} \mathbf{C}$} \\
\cline { 2 - 10 } & $\boldsymbol{A}$ & $\boldsymbol{n}$ & $\boldsymbol{R}^{\mathbf{2}}$ & $\boldsymbol{A}$ & $\boldsymbol{n}$ & $\boldsymbol{R}^{\mathbf{2}}$ & $\boldsymbol{A}$ & $\boldsymbol{n}$ & $\boldsymbol{R}^{\mathbf{2}}$ \\
\hline SMA-13 & 3.319 & 0.919 & 0.98 & 3.043 & 0.913 & 0.98 & 2.656 & 0.905 & 0.97 \\
AC-13 & 2.883 & 0.894 & 0.97 & 2.550 & 0.885 & 0.99 & 2.338 & 0.876 & 0.98 \\
OGFC-13 & 2.440 & 0.847 & 0.98 & 2.363 & 0.835 & 0.99 & 2.113 & 0.824 & 0.99 \\
\hline
\end{tabular}

It can be seen from Table 4 that with the increase of temperature, the parameter $A$ and $n$ decrease, and the $\sigma_{3}-\sigma_{1}$ curves bend down. The increase in amplitude of triaxial strength with confining pressure became larger and larger. Based on the results, a regression/prediction model of triaxial strength considering the effects of temperature and confining pressure for asphalt mixtures is shown in Equation (2).

$$
\sigma_{3 t}=\left(a_{0} t+b_{0}\right) \sigma_{1}^{\left(a_{1} t+b_{1}\right)}+f_{c t}
$$

where $\sigma_{3 t}$ denotes triaxial compressive strength at different temperatures, $\sigma_{1}$ is the confining pressure, $f_{c t}$ is the uniaxial compressive strength at different temperatures, $t$ is the temperature. The parameters of this triaxial strength model are shown in Table 5.

Table 5. Parameters of the triaxial strength model considering the influence of temperature and confining pressure.

\begin{tabular}{cccccc}
\hline Mixture Type & $\boldsymbol{a}_{\mathbf{0}}$ & $\boldsymbol{b}_{\mathbf{0}}$ & $\boldsymbol{a}_{\mathbf{1}}$ & $\boldsymbol{b}_{\mathbf{1}}$ & $\boldsymbol{R}^{\mathbf{2}}$ \\
\hline SMA-13 & -0.033 & 4.664 & $-0.70 \times 10^{-3}$ & 0.947 & 0.97 \\
AC-13 & -0.027 & 3.953 & $-0.90 \times 10^{-3}$ & 0.930 & 0.99 \\
OGFC-13 & -0.016 & 3.123 & $-1.15 \times 10^{-3}$ & 0.893 & 0.98 \\
\hline
\end{tabular}

\subsection{Nonlinear Mohr-Coulomb Failure Criterion}

Based on the triaxial results, the Mohr-Coulomb circles can be drawn, and all the tangent points can be obtained by two Mohr-Coulomb circles tangent to each other. Considering that the Mohr-Coulomb criterion is one of the most popular strength theories in highway engineering, the triaxial compressive test results are plotted in the $\sigma-\tau$ space to investigate the shear failure properties of asphalt mixtures, and the results are shown in Figures $8-10$ (take the results of $60^{\circ} \mathrm{C}$ as example). The data is fitted with linear function and power function respectively, and the nonlinear function is shown in Equation (3).

$$
\tau=a \sigma^{b}+c
$$

where $\sigma$ represents the normal stress in the shear failure plane, $\tau$ is the shear stress in the shear failure plane, $a, b$ and $c$ are constants. In fact, $c$ is cohesion strength when $\sigma=0$. By curve fitting of the test data, all constants obtained are listed in Table 6.

\begin{tabular}{|c|c|c|c|c|c|c|c|c|c|c|c|c|}
\hline \multirow{2}{*}{ Mixture Type } & \multicolumn{4}{|c|}{$40^{\circ} \mathrm{C}$} & \multicolumn{4}{|c|}{$50{ }^{\circ} \mathrm{C}$} & \multicolumn{4}{|c|}{$60^{\circ} \mathrm{C}$} \\
\hline & $a$ & $b$ & $c$ & $R^{2}$ & $a$ & $b$ & $c$ & $R^{2}$ & $a$ & $b$ & $c$ & $R^{2}$ \\
\hline SMA-13 & 0.80 & 0.80 & 0.38 & 0.99 & 0.74 & 0.79 & 0.26 & 0.97 & 0.66 & 0.78 & 0.16 & 0.97 \\
\hline AC-13 & 0.72 & 0.77 & 0.32 & 0.98 & 0.64 & 0.76 & 0.23 & 0.98 & 0.58 & 0.74 & 0.15 & 0.98 \\
\hline OGFC-13 & 0.63 & 0.74 & 0.25 & 0.98 & 0.57 & 0.72 & 0.19 & 0.99 & 0.53 & 0.70 & 0.12 & 0.99 \\
\hline
\end{tabular}

Table 6. Parameters of failure envelope in $\sigma-\tau$ space. 


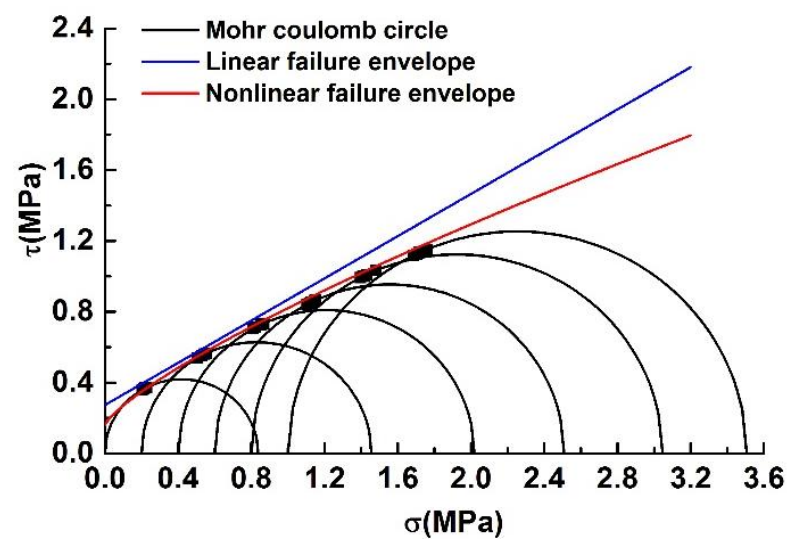

Figure 8. Failure envelope of SMA-13 asphalt mixture in $\sigma-\tau$ space at $60{ }^{\circ} \mathrm{C}$.

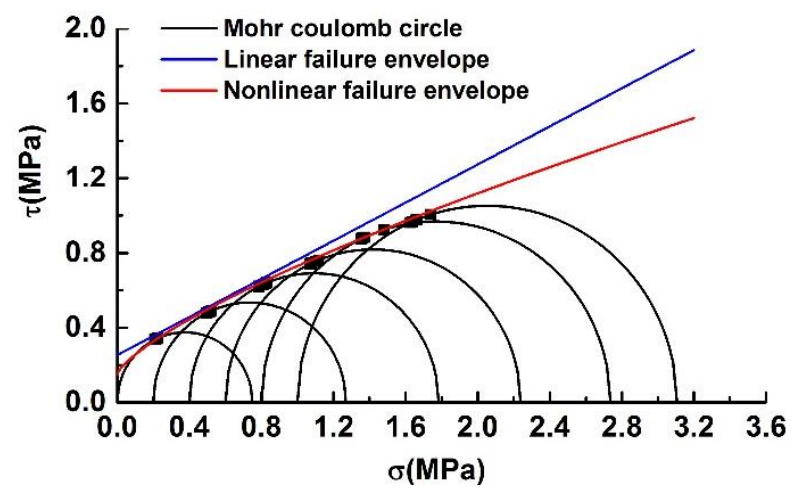

Figure 9. Failure envelope of AC-13 asphalt mixture in $\sigma-\tau$ space at $60{ }^{\circ} \mathrm{C}$.

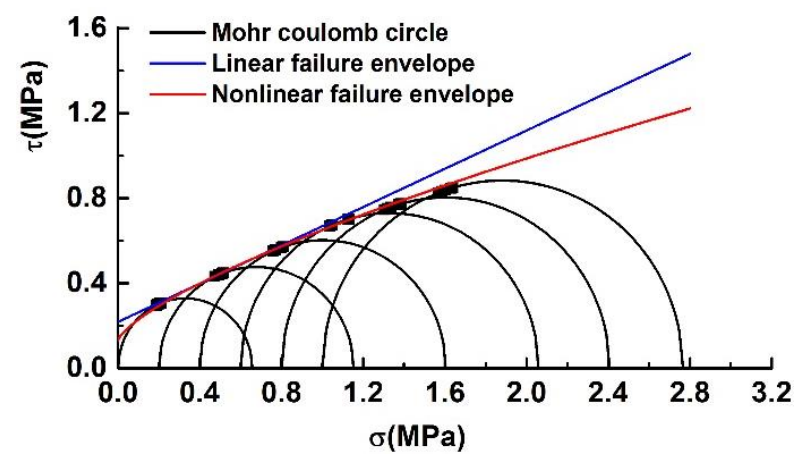

Figure 10. Failure envelope of OGFC-13 asphalt mixture in $\sigma-\tau$ space at $60^{\circ} \mathrm{C}$.

As can be seen from Figures 8-10 that the linear Mohr-Coulomb criterion is not suitable to describe the shear failure behavior of asphalt mixtures, the failure envelopes of asphalt mixtures can be interpolated by a power function. With the increase of temperature, the parameters $a, b$, and $c$ decrease. The failure envelopes of these asphalt mixtures bend down when the confining pressure is close to $0.6 \mathrm{MPa}$. It is clear that the failure strength of asphalt mixtures is highly dependent on the confining pressure and temperature. Moreover, this power functional Mohr-Coulomb failure envelope under the loading speed of $1 \mathrm{~mm} / \mathrm{min}$ can be validated by the nonlinear failure envelope in the $I_{1}-\sqrt{J_{2}}$ space proposed by Wang et al. [15] (where $I_{1}$ represents the first invariant of stress tensor, $J_{2}$ denotes the second invariant of stress deviator). It is also reasonable to predict the failure envelope of asphalt mixtures in $\sigma-\tau$ space considering the influence of temperature and confining pressure as following:

$$
\tau_{t}=\left(m_{0} t+n_{0}\right) \sigma^{\left(m_{1} t+n_{1}\right)}+\left(m_{2} t+n_{2}\right)
$$


where $\sigma$ represents the normal stress in the shear failure plane; $\tau_{t}$ is the shear stress in the shear failure plane at different temperatures; $t$ is the temperature; $m_{0}, n_{0}, m_{1}, n_{1}, m_{2}$, and $n_{2}$ are constants. All the parameters of this model are listed in Table 7.

Table 7. Parameters of the $\sigma-\tau$ model considering the influence of temperature and confining pressure.

\begin{tabular}{cccccccc}
\hline Mixture Type & $\boldsymbol{m}_{\mathbf{0}}$ & $\boldsymbol{n}_{\mathbf{0}}$ & $\boldsymbol{m}_{\mathbf{1}}$ & $\boldsymbol{n}_{\mathbf{1}}$ & $\boldsymbol{m}_{\mathbf{2}}$ & $\boldsymbol{n}_{\mathbf{2}}$ & $\boldsymbol{R}^{\mathbf{2}}$ \\
\hline SMA-13 & $-7.0 \times 10^{-3}$ & 1.083 & $-0.10 \times 10^{-2}$ & 0.840 & $-1.10 \times 10^{-2}$ & 0.817 & 0.99 \\
AC-13 & $-6.9 \times 10^{-3}$ & 0.990 & $-0.15 \times 10^{-2}$ & 0.832 & $-0.85 \times 10^{-2}$ & 0.658 & 0.98 \\
OGFC-13 & $-5.0 \times 10^{-3}$ & 0.827 & $-0.20 \times 10^{-2}$ & 0.820 & $-0.65 \times 10^{-2}$ & 0.512 & 0.98 \\
\hline
\end{tabular}

Consider linear case, i.e., $b=1$ and $a=\tan \varphi$, where $\varphi$ is defined as friction angle, linear Mohr-Coulomb failure criterion is given in Equation (5) $[27,28]$. Furthermore, the strength parameters that are cohesion strength and friction angle obtained by linear Mohr-Coulomb theory are shown in Table 8 .

$$
\tau=\sigma \tan \varphi+c
$$

Table 8. Strength parameters of asphalt mixtures by linear failure envelope.

\begin{tabular}{ccccccc}
\hline \multirow{2}{*}{ Mixture Type } & \multicolumn{2}{c}{$4 \mathbf{~}^{\circ} \mathbf{C}$} & \multicolumn{2}{c}{$50^{\circ} \mathbf{C}$} & \multicolumn{2}{c}{$\mathbf{6 0}{ }^{\circ} \mathbf{C}$} \\
\cline { 2 - 7 } & $c$ & $\boldsymbol{c}$ & $c$ & $\boldsymbol{c}$ & $c$ & $\boldsymbol{c}$ \\
\hline SMA-13 & 0.518 & 35.030 & 0.389 & 32.129 & 0.273 & 30.795 \\
AC-13 & 0.475 & 31.048 & 0.323 & 29.249 & 0.253 & 27.022 \\
OGFC-13 & 0.391 & 27.474 & 0.293 & 25.641 & 0.218 & 24.228 \\
\hline
\end{tabular}

Table 8 and Figure 11 show that according to the linear Mohr-Coulomb theory, the cohesion strength of asphalt mixtures decreases with the increase of temperature; the friction angle slightly decreases with temperature. Both cohesion strength and friction angle of asphalt mixture do not change with confining pressure. In the Mohr-Coulomb criterion, there are two important constants included, i.e., the cohesion strength $c$ and friction angle $\varphi$. The expression of friction angle $\varphi$ for asphalt mixtures can be obtained as follows.

$$
\tan \varphi=\tau^{\prime}=\frac{\partial \tau}{\partial \sigma}=a b \sigma^{b-1}
$$

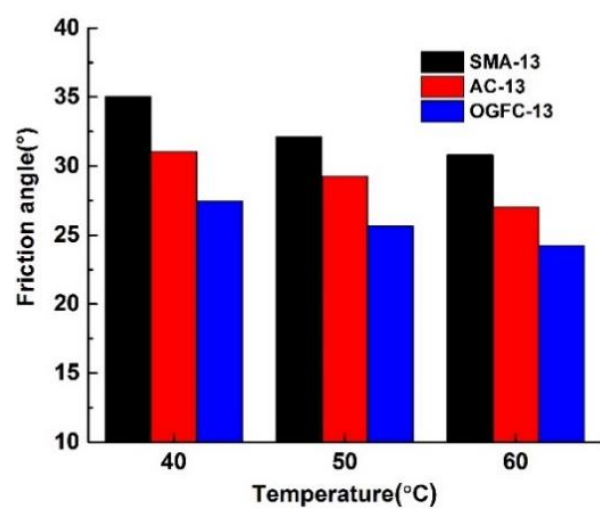

(a)

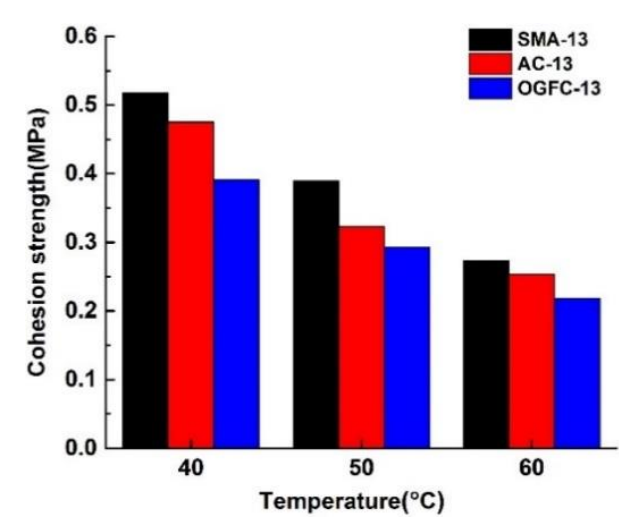

(b)

Figure 11. Cohesion strength and friction angle by linear failure envelope. (a) The friction angle by linear failure envelope; (b) The cohesion strength by linear failure envelope. 
Change the partial differential to ordinary differential, and then

$$
\varphi=\arctan \left(a b \sigma^{b-1}\right)
$$

In addition, the tangent equation passing through the point $\left(\sigma_{m}, \tau_{m}\right)$ can be derived from Equation (3)

$$
\tau=\tau_{m}+\tau^{\prime}\left(\sigma-\sigma_{m}\right)=\tau_{m}+a b\left(\sigma_{m}\right)^{b-1}\left(\sigma-\sigma_{m}\right)
$$

Let $\sigma=0$, then Equation (8) gives

$$
\tau_{\sigma=0}=\tau_{m}-a b \sigma_{m}{ }^{b}
$$

Finally, denote $\tau_{\sigma=0}$ as $C$, and substitute Equation (3) into Equation (9), then one can obtain the expression for cohesion strength as

$$
C=a(1-b) \sigma_{m}^{b}+c
$$

where $C$ is cohesion strength under different confining pressure, $a, b, c$ are parameters in Equation (3).

As a result, the nonlinear evolutional laws of Mohr-Coulomb strength parameters cohesion strength $C$ and friction angle $\varphi$ are obtained and shown in Table 9.

Table 9. Strength parameters of asphalt mixtures by nonlinear failure envelope.

\begin{tabular}{cccccccc}
\hline \multirow{2}{*}{$\begin{array}{c}\text { Mixture } \\
\text { Type }\end{array}$} & $\begin{array}{c}\text { Confining } \\
\text { Pressure }\end{array}$ & \multicolumn{2}{c}{$\mathbf{4 0}{ }^{\circ} \mathbf{C}$} & \multicolumn{2}{c}{$\mathbf{5 0}{ }^{\circ} \mathbf{C}$} & \multicolumn{2}{c}{$\mathbf{6 0}{ }^{\circ} \mathbf{C}$} \\
\cline { 3 - 8 } & & $\boldsymbol{c}$ & $\boldsymbol{\varphi}$ & $\boldsymbol{c}$ & $\boldsymbol{\varphi}$ & $\boldsymbol{c}$ & $\boldsymbol{\varphi}$ \\
\hline \multirow{2}{*}{ SMA-13 } & 0.2 & 0.516 & 33.666 & 0.372 & 32.516 & 0.249 & 30.565 \\
& 0.4 & 0.552 & 32.163 & 0.413 & 30.431 & 0.287 & 28.119 \\
& 0.6 & 0.594 & 30.769 & 0.448 & 29.052 & 0.320 & 26.621 \\
& 0.8 & 0.630 & 29.782 & 0.483 & 27.959 & 0.352 & 25.459 \\
& 1.0 & 0.664 & 29.004 & 0.517 & 27.093 & 0.381 & 24.564 \\
\hline AC-13 & 0.2 & 0.453 & 30.606 & 0.334 & 28.848 & 0.241 & 27.096 \\
& 0.4 & 0.491 & 28.776 & 0.374 & 26.384 & 0.279 & 24.408 \\
& 0.6 & 0.525 & 27.466 & 0.405 & 25.003 & 0.310 & 22.782 \\
& 0.8 & 0.561 & 26.376 & 0.437 & 23.892 & 0.342 & 21.521 \\
& 1.0 & 0.595 & 25.487 & 0.467 & 22.994 & 0.370 & 20.600 \\
\hline OGFC-13 & 0.2 & 0.370 & 27.445 & 0.296 & 25.660 & 0.217 & 24.595 \\
& 0.4 & 0.414 & 24.982 & 0.334 & 23.151 & 0.254 & 21.776 \\
& 0.6 & 0.447 & 23.596 & 0.366 & 21.540 & 0.288 & 19.937 \\
& 0.8 & 0.478 & 22.546 & 0.402 & 20.187 & 0.316 & 18.753 \\
& 1.0 & 0.507 & 21.707 & 0.423 & 19.494 & 0.341 & 17.844 \\
\hline
\end{tabular}

In Figures 12-14, the dotted lines from top to bottom represent the friction angle and cohesion strength of SMA-13, AC-13, and OGFC-13 obtained by linear Mohr-Coulomb theory, respectively.

It can be seen from Figures 12-14 that the linear Mohr-Coulomb theory cannot reflect the nonlinear variation of the cohesion strength and friction angle with testing conditions. Besides this, the linear Mohr-Coulomb theory in current asphalt pavement design produces a relatively large deviation in the calculation of cohesion strength and friction angle, which makes the design of pavement materials not accurate. Therefore, it is more appropriate to use the nonlinear failure criterion in the design of the asphalt pavement materials and structures.

As can be seen from Table 9, the increase of temperature degrades the triaxial strength of asphalt mixtures. Compared with the continuous-graded AC-13 asphalt mixture and the open-graded OGFC-13 asphalt mixture, the gap-graded SMA-13 asphalt mixture exhibits better performance on the resistance to shear damage under complex stress conditions. It is mainly due to the framework dense structure of SMA-13 asphalt mixture was formed by coarse aggregates interlocked with each other and fine aggregates filled with voids. In addition, there are some fibers in the SMA-13 asphalt mixture which improves the shear strength $[34,35]$. Considering the overloading phenomenon that generally 
exists in China, the SMA-13 asphalt mixture is recommended as the upper layer material to improve the shear performance of the asphalt pavement structure.

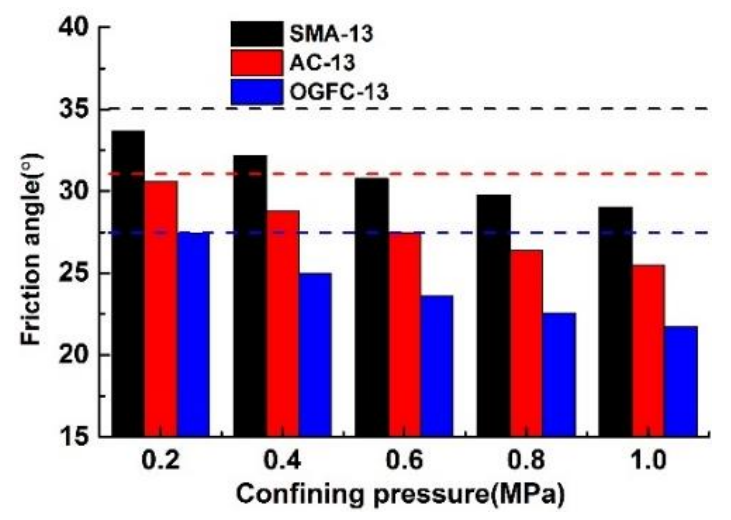

(a)

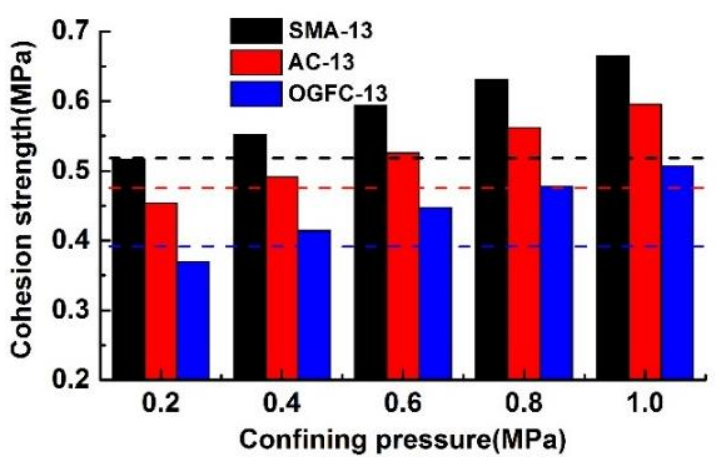

(b)

Figure 12. Friction angle and cohesion strength of asphalt mixtures with linear and nonlinear Mohr-Coulomb failure criterions at $40{ }^{\circ} \mathrm{C}$. (a) The friction angle of asphalt mixtures with linear and nonlinear Mohr-Coulomb failure criterions at $40{ }^{\circ} \mathrm{C}$; (b) The cohesion strength of asphalt mixtures with linear and nonlinear Mohr-Coulomb failure criterions at $40{ }^{\circ} \mathrm{C}$.

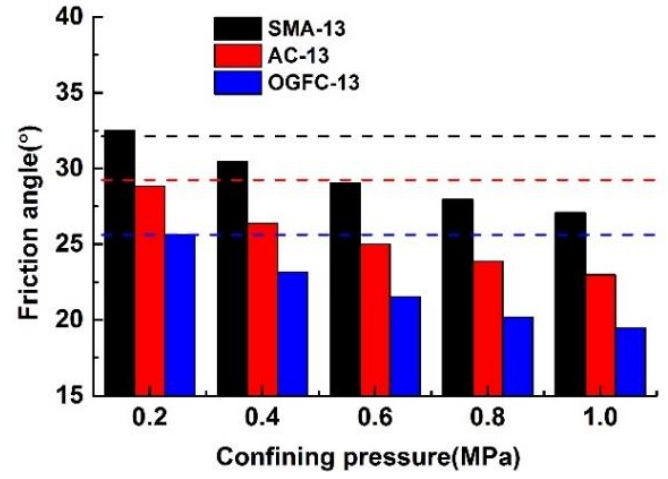

(a)

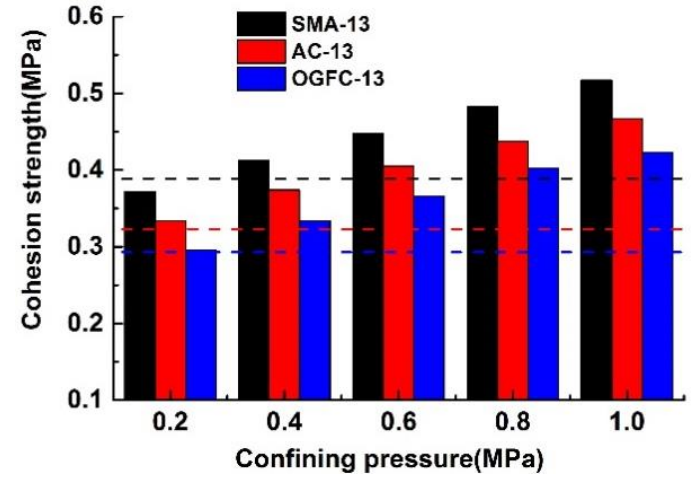

(b)

Figure 13. Friction angle and cohesion strength of asphalt mixtures with linear and nonlinear Mohr-Coulomb failure criterions at $50{ }^{\circ} \mathrm{C}$. (a) The friction angle of asphalt mixtures with linear and nonlinear Mohr-Coulomb failure criterions at $50{ }^{\circ} \mathrm{C}$; (b) The cohesion strength of asphalt mixtures with linear and nonlinear Mohr-Coulomb failure criterions at $50{ }^{\circ} \mathrm{C}$.

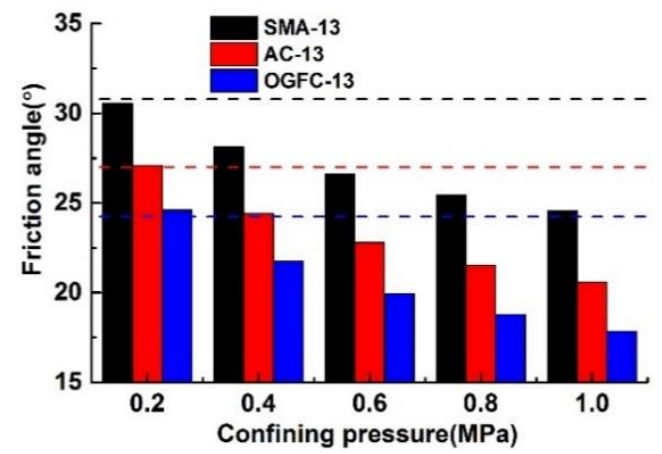

(a)

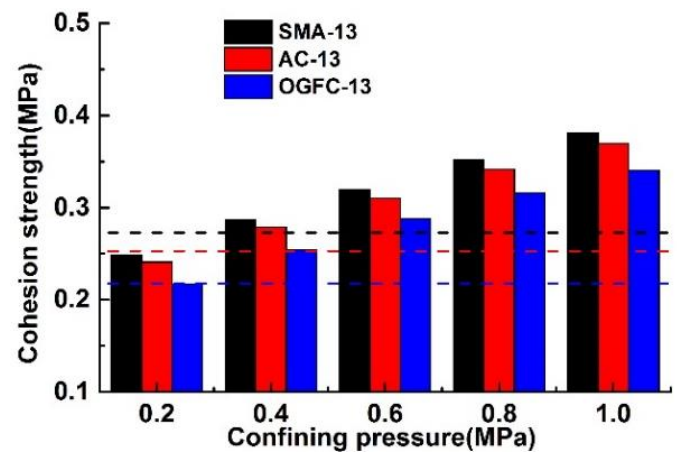

(b)

Figure 14. Friction angle and cohesion strength of asphalt mixtures with linear and nonlinear Mohr-Coulomb failure criterions at $60{ }^{\circ} \mathrm{C}$. (a) The friction angle of asphalt mixtures with linear and nonlinear Mohr-Coulomb failure criterions at $60{ }^{\circ} \mathrm{C}$; (b) The cohesion strength of asphalt mixtures with linear and nonlinear Mohr-Coulomb failure criterions at $60^{\circ} \mathrm{C}$. 


\section{Conclusions and Recommendations}

Triaxial compressive tests were conducted with confining pressure levels ranges from 0 to $1 \mathrm{MPa}$ at $40{ }^{\circ} \mathrm{C}, 50{ }^{\circ} \mathrm{C}$, and $60{ }^{\circ} \mathrm{C}$. The results could be applied to investigate the shear failure behavior of asphalt mixtures. The following conclusions can be drawn:

(1) The failure behavior of asphalt mixtures SMA-13, AC-13, and OGFC-13 are affected significantly by the confining pressure and temperature. It was observed that the increase of temperature degrades the triaxial strength of asphalt mixtures mainly due to the decrease of cohesion strength; when the confining pressure increases, the shear failure strength of asphalt mixture increases with the increase of cohesion strength, while the friction angle of asphalt mixtures decreases.

(2) The linear Mohr-Coulomb criterion is not suitable to describe the failure behavior of asphalt mixtures since its shear failure envelope is highly affected by the testing conditions. Therefore, a nonlinear regression/prediction model of shear strength for asphalt mixtures considering the influence of temperature and confining pressure was proposed. The nonlinear evolutional laws of cohesion strength and friction angle are also proposed. It is reasonable to use the nonlinear failure criterion in the design of asphalt pavement materials and structures.

(3) Compared with the continuous-graded AC-13 asphalt mixture and the open-graded OGFC-13 asphalt mixture, the gap-graded SMA-13 asphalt mixture exhibits better performance on the resistance to shear damage under complex stress condition. Considering the overloading phenomenon that generally exists in China, the SMA-13 asphalt mixture is recommended as the upper layer material to improve the shear performance of asphalt pavement structure.

(4) Triaxial compressive tests should be done at different loading rates in the future. And further study is required for asphalt mixtures with varying bitumen-aggregate ratio, or varying amount of asphalt binder and so on in the lab to improve the shear resistance of asphalt mixtures at high-temperature conditions.

Author Contributions: Conceptualization, T.H. and S.L.; Data curation, T.H., S.Q. and H.L.; Formal analysis, T.H. and H.Y.; Funding acquisition, T.H.; Methodology, T.H. and S.L.; Project administration, T.H. and H.L.; Resources, T.H. and S.L.; Validation, S.L.; Writing—original draft, T.H., S.Q., and H.Y.; Writing-review and editing, T.H. and S.L.

Funding: This research was funded by the National Natural Science Foundation of China, grant number [51608055, 51878076, 51608058], National Key R\&D Program of China, grant number [2018YFB1600100], Natural Science Foundation of Hunan Province, grant number [2019JJ40297, 2018JJ2433, 2018JJ3550], the education department of Hunan province, grant number [18B143,18B144], Open Fund of the Key Laboratory of Highway Engineering of Ministry of Education (Changsha University of Science \& Technology), grant number [kfj160201].

Conflicts of Interest: The authors declare no conflict of interest.

\section{References}

1. Zhang, J.; Peng, J.; Zheng, J.; Dai, L.; Yao, Y. Prediction of Resilient Modulus of Compacted Cohesive Soils in South China. Int. J. Geomech. 2019. [CrossRef]

2. Sun, L. Behavior of Asphalt Pavement Structure; Tongji University Press: Shanghai, China, 2013.

3. Du, Y.; Chen, J.; Han, Z.; Liu, W. A review on solutions for improving rutting resistance of asphalt pavement and test methods. Constr. Build. Mater. 2018, 168, 893-905. [CrossRef]

4. Li, J.; Zhang, J.; Qian, G.; Zheng, J.; Zhang, Y. Three-Dimensional Simulation of Aggregate and Asphalt Mixture Using Parameterized Shape and Size Gradation. J. Mater. Civ. Eng. 2019, 31, 04019004. [CrossRef]

5. Zhang, K.; Zhang, Z.; Luo, Y. Inspection method and evaluation standard based on cylindrical core sample for rutting resistance of asphalt pavement. Measurement 2018, 117, 241-251. [CrossRef]

6. Lv, S.; Xia, C.; Liu, C.; Zheng, J.; Zhang, F. Fatigue equation for asphalt mixture under low temperature and low loading conditions. Constr. Build. Mater. 2019, 211, 1085-1093. [CrossRef]

7. Hofko, B. Addressing the permanent deformation behavior of hot mix asphalt by triaxial cyclic compression testing with cyclic confining pressure. J. Traffic Transp. Eng. 2015, 2, 17-29. [CrossRef]

8. Carpenter, S.H.; Freeman, T.J. Characterizing pavement deformation in asphalt concrete placed over Portland concrete pavements. Transp. Res. Rec. TRB 1986, 1070, 30-41. 
9. Huang, T.; Pan, Q.; Jin, J.; Zheng, J.; Wen, P. Continuous constitutive model for bimodulus materials with meshless approach. Appl. Math. Model. 2019, 66, 41-58. [CrossRef]

10. Zhou, F.; Chen, D.H.; Scullion, T.; Bilyeu, J. Case Study: Evaluation of laboratory test methods to characterize permanent deformation properties of asphalt mixes. Int. J. Pavement Eng. 2003, 4, 155-164. [CrossRef]

11. Martin, A.E.; Park, D. Use of the asphalt pavement analyzer and repeated simple shear test at constant height to augment Superpave volumetric mix design. J. Transp. Eng. 2003, 129, 522-530. [CrossRef]

12. Ji, X.; Zheng, N.; Hou, Y.; Niu, S. Application of asphalt mixture shear strength to evaluate pavement rutting with accelerated loading facility (ALF). Constr. Build. Mater. 2013, 41, 1-8. [CrossRef]

13. Zhang, J.; Yang, J.; Kim, Y.R. Characterization of mechanical behavior of asphalt mixtures under partial triaxial compression test. Constr. Build. Mater. 2015, 79, 136-144. [CrossRef]

14. Bi, Y.; Sun, L. Research on test method of asphalt mixture's shearing properties. J. Tongji Univ. (Nat. Sci.) 2005, 33, 1036-1040.

15. Wang, J.; Molenaar, A.A.; van de Ven, M.F.; Wu, S. Behaviour of asphalt concrete mixtures under tri-axial compression. Constr. Build. Mater. 2016, 105, 269-274. [CrossRef]

16. Krishnan, J.M.; Rajagopal, K.R. Triaxial testing and stress relaxation of asphalt concrete. Mech. Mater. 2004, 36, 849-864. [CrossRef]

17. White, G. Shear stresses in an asphalt surface under various aircraft braking conditions. Int. J. Pavement Res. Technol. 2016, 9, 89-101. [CrossRef]

18. Wang, H.; Al-Qadi, I.L. Near-Surface Pavement Failure Under Multiaxial Stress State in Thick Asphalt Pavement. Transp. Res. Rec. J. Transp. Res. Board 2010, 2154, 91-99. [CrossRef]

19. Yin, H.; Zhu, Y.; Yin, C. Study on the Mechanical Properties of Tack Coat between Asphalt Layers by Interlaminar Shear Tests. Appl. Mech. Mater. 2013, 361-363, 1490-1494. [CrossRef]

20. Zhang, J.; Li, J.; Yao, Y.; Zheng, J.; Gu, F. Geometric Anisotropy Modeling and Shear Behavior Evaluation of Graded Crushed Rocks. Constr. Build. Mater. 2018, 183, 346-355. [CrossRef]

21. Low, B.H.; Tan, S.A.; Fwa, T.F. Analysis of Marshall test behavior with triaxial test determined material properties. Test. Eval. 1993, 21, 192-198. [CrossRef]

22. Fwa, T.F.; Tan, S.A.; Zhu, L.Y. Reexamining of $C-\phi$ concept for asphalt paving mix design. J. Transp. Eng. 2001, 127, 67-73. [CrossRef]

23. Zhao, Y.; Tang, J.; Liu, H. Construction of triaxial dynamic modulus master curve for asphalt mixtures. Procedia Eng. 2012, 37, 21-26. [CrossRef]

24. Lv, S.; Liu, C.; Chen, D.; Zheng, J.; You, Z.; You, L. Normalization of fatigue characteristics for asphalt mixtures under different stress states. Constr. Build. Mater. 2018, 177, 33-42. [CrossRef]

25. Behnood, A.; Olek, J. Rheological properties of asphalt binders modified with styrene-butadiene-styrene (SBS), ground tire rubber (GTR), or polyphosphoric acid (PPA). Constr. Build. Mater. 2017, 151, 464-478. [CrossRef]

26. Liang, M.; Liang, P.; Fan, W.; Qian, C.; Xin, X.; Shi, J.; Nan, G. Thermo-rheological behavior and compatibility of modified asphalt with various styrene-butadiene structures in SBS copolymers. Mater. Des. 2015, 88, 177-185. [CrossRef]

27. Huang, T.; Qi, S.; Yang, M.; Lv, S.; Liu, H.; Zheng, J. Strength criterion of asphalt mixtures in three-dimensional stress states under freeze-thaw conditions. Appl. Sci. 2018, 8, 1302. [CrossRef]

28. Zheng, J.; Huang, T. Study on triaxial test method and failure criterion of asphalt mixture. J. Traffic Transp. Eng. (Engl. Ed.) 2015, 2, 93-106. [CrossRef]

29. Žiliūtè, L.; Motiejūnas, A.; Kleizienè, R.; Gribulis, G.; Kravcovas, I. Temperature and Moisture Variation in Pavement Structures of the Test Road. Transp. Res. Procedia 2016, 14, 778-786. [CrossRef]

30. Higashiyama, H.; Sano, M.; Nakanishi, F.; Takahashi, O.; Tsukuma, S. Field measurements of road surface temperature of several asphalt pavements with temperature rise reducing function. Case Stud. Constr. Mater. 2016, 4, 73-80. [CrossRef]

31. Ouyang, C.; Wang, S.; Zhang, Y.; Zhang, Y. Low-density polyethylene/silica compound modified asphalts with high-temperature storage stability. J. Appl. Polym. Sci. 2010, 101, 472-479. [CrossRef]

32. Huang, T.; Zheng, J.; Lv, S.; Zhang, J.; Wen, P.; Bailey, C.G. Failure criterion of an asphalt mixture under three-dimensional stress state. Constr. Build. Mater. 2018, 170, 708-715. [CrossRef]

33. Dołżycki, B.; Judycki, J. Behaviour of Asphalt Concrete in Cyclic and Static Compression Creep Test with and without Lateral Confinement. Road Mater. Pavement Des. 2008, 9, 207-225. [CrossRef] 
34. Goetz, W.H.; Schaub, J.H. Triaxial Testing of Bituminous Mixtures: Technical Report 6; Purdue University: West Lafayette, IN, USA, 1959.

35. Shen, J. Asphalt and Asphalt Mixture Performance; China Communications Press: Beijing, China, 2001.

(c)

(C) 2019 by the authors. Licensee MDPI, Basel, Switzerland. This article is an open access article distributed under the terms and conditions of the Creative Commons Attribution (CC BY) license (http:/ / creativecommons.org/licenses/by/4.0/). 